05

\title{
Экспериментальное исследование разрушения преград с различными физико-механическими характеристиками при ударном нагружении
}

\author{
(C) В.М. Захаров, В.В. Буркин
}

Научно-исследовательский институт прикладной математики и механики Национального исследовательского Томского государственного университета, 634050 Томск, Россия

e-mail: zakharov_vm@list.ru

Поступило в Редакцию 16 ноября 2017 г.

В окончательной редакции 28 сентября 2018 г.

Принято к публикации 12 февраля 2019 г.

\begin{abstract}
Экспериментально исследовано разрушение гомогенных преград, имеющих различные физикомеханические характеристики, при взаимодействии с высокопрочными стальными ударниками. Сравнимость результатов для разных типов преград обеспечивалась на основе весовой эквивалентности - равенства веса по толщине для единицы площади преграды. Начальная скорость взаимодействия изменялась в диапазоне $50-800 \mathrm{~m} / \mathrm{s}$. Двухракурсной рентгеноимпульсной съемкой осуществлялась регистрация движения ударника после пробития преграды. Обработкой рентгенограмм получены значения запреградной скорости ударника в зависимости от его начальных скоростей соударения. пронализированы особенности разрушения преград и их защитные свойства путем построения диаграмм пробития.
\end{abstract}

DOI: 10.21883/JTF.2019.07.47793.2564

\section{Введение}

Повышение защитных свойств преград является важнейшей научно-практической задачей. В конструкциях изделий, подвергаемых интенсивным ударным нагрузкам, активно используются различные материалы с повышенными прочностными характеристиками и различные типы преград, например, гомогенные, слоистые. Сравнительный анализ гомогенных и слоистых преград представлен в работе [1].

Исследование закономерностей разрушения преград конечной толщины, разнообразие типов разрушения привели к необходимости более детального анализа деформирования тыльной поверхности преград. Характер разрушения тыльной поверхности преград в случае их пробития удлиненными стержневыми ударниками, разрушающимися в процессе взаимодействия, обсуждался в работе [2].

Целью настоящей работы является исследование характера разрушения различных видов преград при высокоскоростном ударном взаимодействии с высокопрочными недеформируемыми ударниками.

\section{Методика эксперимента}

Для оценки стойкости преград к сквозному разрушению и прогнозирования параметров запреградного потока важны характеристики предельной пластичности материала преград при соударении. Для подобного анализа полезными оказываются измерения осевой деформации $S_{b}$ тыльной поверхности преграды (максимально- го выпучивания вдоль оси удара). С этой целью была разработана методика построения диаграмм пробития, на которых строятся графики зависимостей глубины проникания ударника $L_{b}$ (пути ударника) в преграду толщиной $b$ и осевой деформации $S_{b}$ от скорости взаимодействия. Расстояние между этими графиками показывает изменение толщины преграды в процессе взаимодействия по мере возрастания скорости удара.

Исследование особенностей разрушения преград конечной толщины в диапазоне относительно низких скоростей взаимодействия, где ударники не разрушаются, проводилось в экспериментах с высокопрочным стальным ударником 6.1Б-32 по преградам различной прочности и плотности. Ударник имеет следующие параметры: диаметр $d_{0}=6.1 \mathrm{~mm}$, оживальная головная часть высотой $h=11.2 \mathrm{~mm}$, масса ударника $5.5 \mathrm{~g}$.

Метание ударников производилось из пороховой баллистической установки калибром $8 \mathrm{~mm}$, скорость метания (соударения) $V_{0}$ изменялась от 50 до $800 \mathrm{~m} / \mathrm{s}$. Скорость ударников определялась индукционными измерителями.

В первой серии опытов использовались пластичные стальные преграды из Ст3. Цель этих опытов - отработка методики построения диаграмм пробития преград.

Вторая серия опытов проводилась с эквивалентными преградами из стали средней твердости Ст,69“Ш, прочного алюминиевого сплава Ал-102 и прочного титанового сплава ВТ-6. Толщина преград подбиралась из условия равенства веса, т. е. веса единицы площади всех преград были равны. Прочностные характеристики исследуемых материалов подбирались близкими к максимальным для своих типов сплавов. Такие условия экви- 
Таблица 1. Характеристика исследуемых преград

\begin{tabular}{c|c}
\hline Тип материала & Механические характеристики \\
\hline Стальной лист обыкновенного качества Ст3 & $H B(120-140)$ \\
\hline Стальной лист средней твердости Ст,69“Ш & $H B(321-363)$ \\
\hline Алюминиевый высокопрочный сплав Ал-102 & $\rho=2.75 \mathrm{~g} / \mathrm{cm}^{3} ; H B 143$ \\
\hline Титановый сплав ВТ-6. Листовой прокат & $\rho=4.45 \mathrm{~g} / \mathrm{cm}^{3} ; H B 302$
\end{tabular}

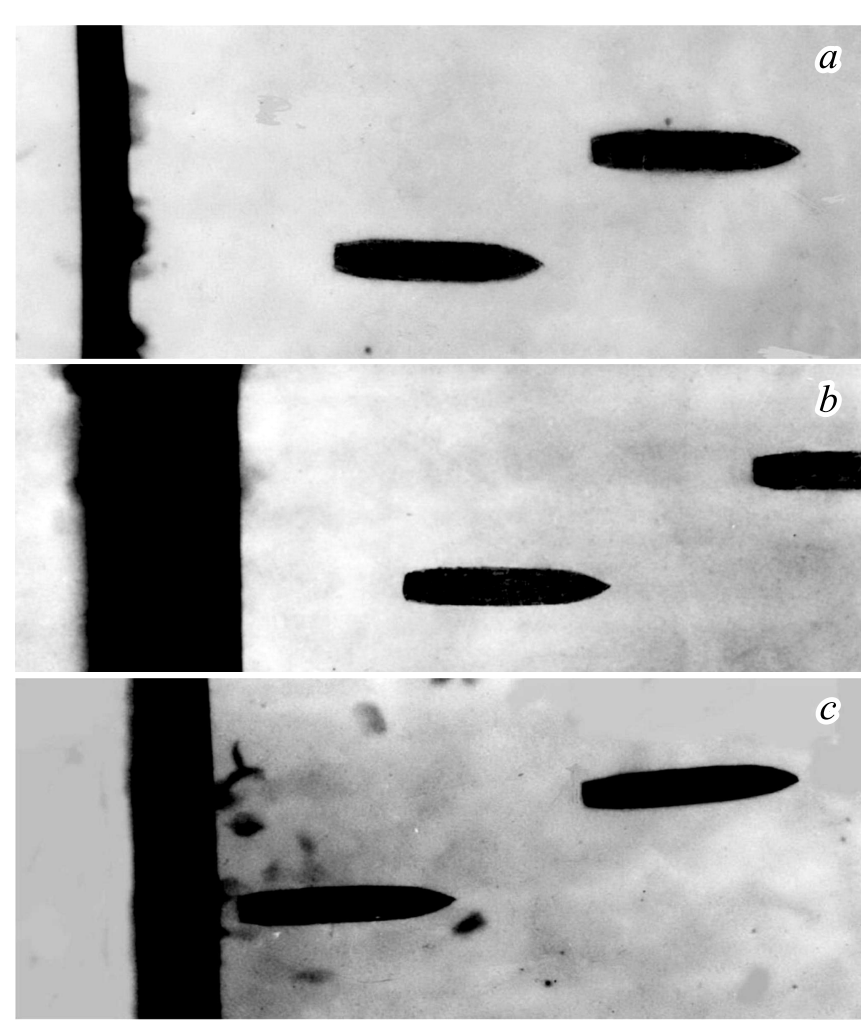

Рис. 1. Двухэкспозиционные рентгенограммы движения ударника 6.1Б-32 за преградой: $a-$ преграда Ст,,69“Ш, $V_{0}=408 \mathrm{~m} / \mathrm{s}, \Delta \tau=200 \mu \mathrm{s}, V_{s}=208 \mathrm{~m} / \mathrm{s} ; b-$ преграда Ал-102, $V_{0}=410 \mathrm{~m} / \mathrm{s}, \Delta \tau=400 \mu \mathrm{s}, V_{s}=125 \mathrm{~m} / \mathrm{s} ; c-$ преграда ВТ-6, $V_{0}=547 \mathrm{~m} / \mathrm{s}, \Delta \tau=130 \mu \mathrm{s}, V_{s}=387 \mathrm{~m} / \mathrm{s}$.

валентности позволяют провести сравнительный анализ особенностей разрушения и стойкости всех преград. Описание преград приведено в табл. 1, где обозначены $H B$ - твердость по Бринеллю, $\rho$ - плотность материала преграды.

Регистрация процесса взаимодействия ударника с преградой осушествлялась методом двухэкспозиционной съемки на одну кассету двумя рентгеноимпульсными аппаратами РИНА-3Б/6 с задержкой $\Delta \tau$ времени срабатывания между ними. Обработкой рентгенограмм определялась скорость запреградного потока $V_{s}$. Типичные рентгенограммы представлены на рис. 1.
Опыты проводились в условиях нормального удара, когда вектор скорости совпадает с продольной осью ударника и нормалью к поверхности преграды.

\section{Характер разрушения преград}

На рис. 2-5 эти эксперименты для всех преград представлены в виде обобщенных диаграмм пробития, где наряду с зависимостями $L_{b}\left(V_{0}\right)$ и $S_{b}\left(V_{0}\right)$ даны зависимости запреградной скорости $V_{s}\left(V_{0}\right)$. Предварительный анализ для преграды ВТ-6 был представлен в работе [3].

На диаграммах отмечены характерные координаты: - абсциссы, описывающие состояние тыльной поверхности преграды: НПК (FPD) - начало образования пластического купола (Formation of the Plastic Dome); РПК

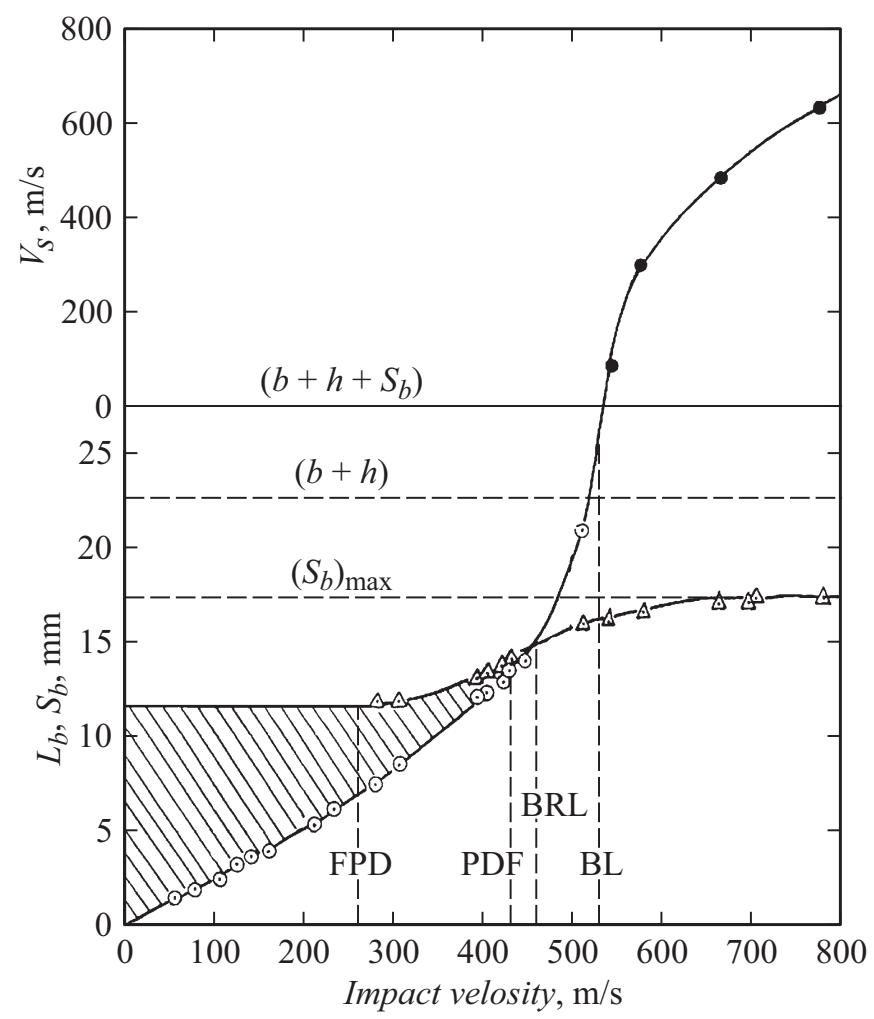

Pис. 2. Диаграмма пробития преграды Ст3 ударником 6.1Б-32, сечение преграды заштриховано; графическими знаками обозначены экспериментальные данные для зависимостей: о $L_{b}\left(V_{0}\right) ; \Delta-S_{b}\left(V_{0}\right) ; \bullet-V_{s}\left(V_{0}\right)$. 


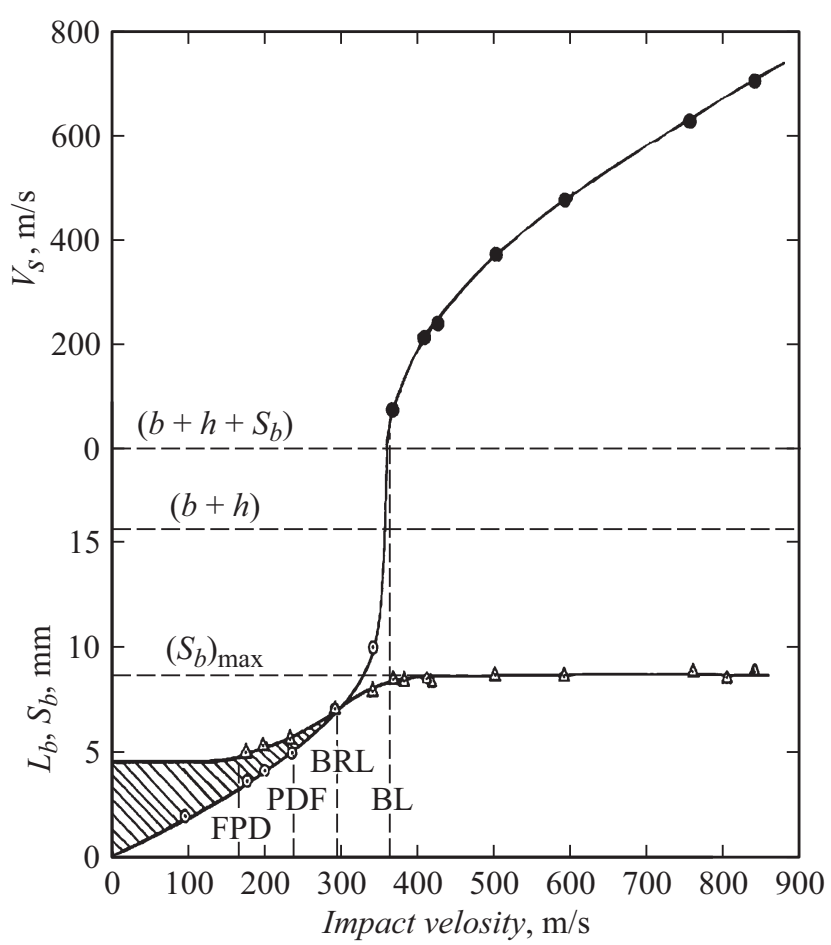

Pис. 3. Диаграмма пробития стальной преграды Ст,69“Ш ударником 6.1Б-32, сечение преграды заштриховано; обозначения кривых - те же.

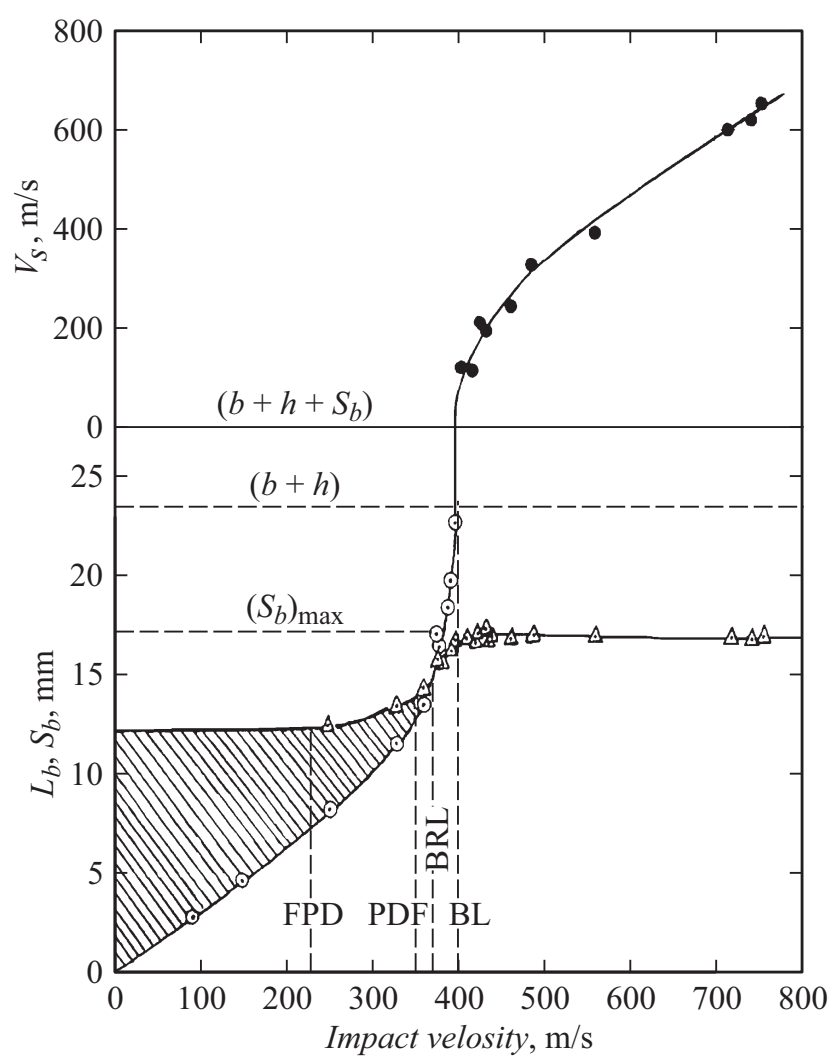

Рис. 4. Диаграмма пробития преграды из алюминиевого сплава Ал-102 ударником 6.1Б-32, сечение преграды заштриховано; обозначения кривых - те же.

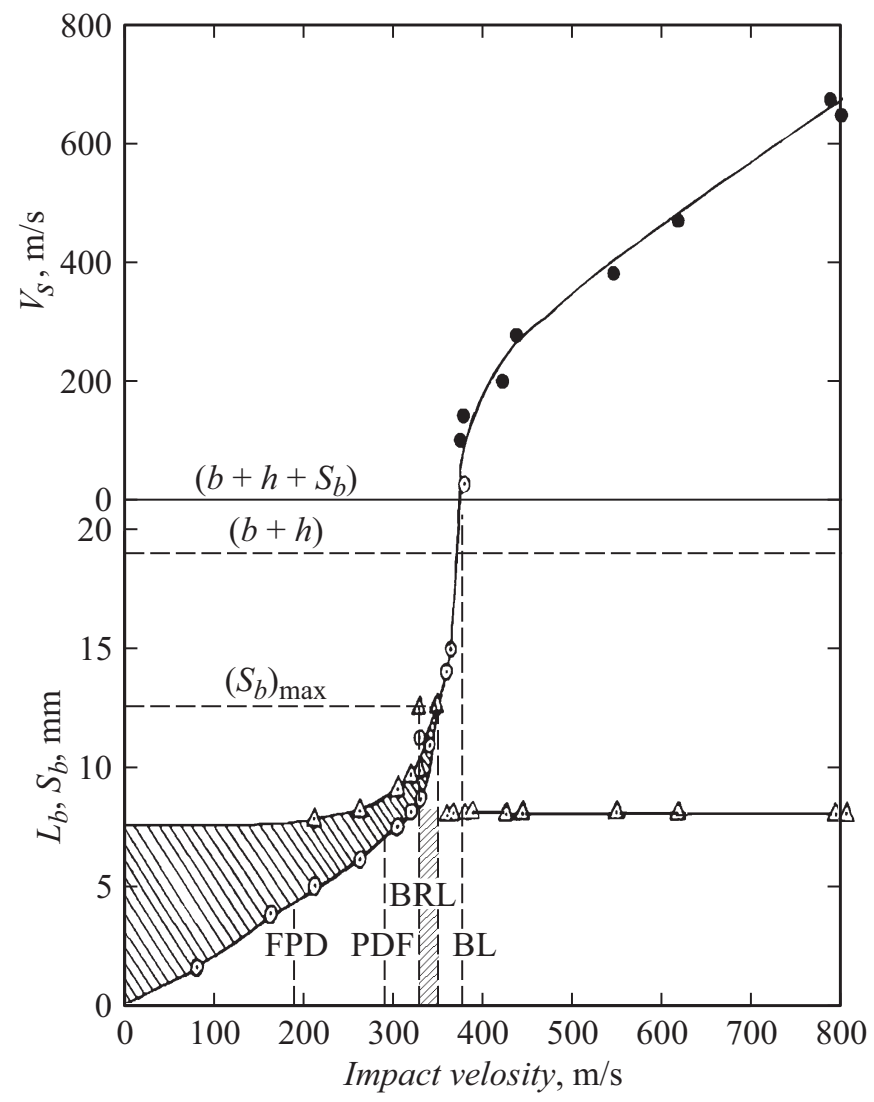

Pис. 5. Диаграмма пробития преграды из титанового сплава ВТ-6 ударником 6.1Б-32, сечение преграды и зона „срезания пробки“ заштрихованы; обозначения кривых - те же.

(PDF) - разрыв (появление первых трещин) пластического купола (Plastic Dome Fracture); ПТП (BRL) предел тыльной прочности - нарушение сплошности преграды (Back Resistance Limit); ПСП (BL) - предел сквозного пробития (Ballistic Limit);

- ординаты, характеризующие путь ударника в преграде и деформацию ее тыльной поверхности: $\left(S_{b}\right)_{\max }-$ максимальная деформация тыльной поверхности преграды; $(b+h)$ и $\left(b+h+S_{b}\right)-$ выход ударника из пластического купола $(h-$ высота головной части ударника).

Ордината $\left(b+h+S_{b}\right)$ соответствует моменту ПСП, когда ударник может удерживаться в преграде лишь силами трения по его цилиндрической поверхности и при дальнейшем незначительном повышении скорости встречи ударник пробивает преграду, имея запреградную скорость $V_{s}$.

Взаимоположение кривых $L_{b}\left(V_{0}\right)$ и $S_{b}\left(V_{0}\right)$ позволяет более точно определять моменты образования и разрыва тыльного купола и собственно момент сквозного разрушения ПСП. Анализ зависимости $S_{b}\left(V_{0}\right)$ дает возможность оценить размеры срезаемой пробки, зоны „прокола“ и „откола“. 
Таблица 2. Анализ диаграмм пробития, ударник 6.1Б-32

\begin{tabular}{|c|c|c|c|c|}
\hline \multirow{2}{*}{ Параметр диаграммы } & \multicolumn{4}{|c|}{ Материал преграды } \\
\hline & Ст3 & 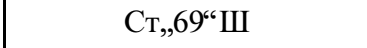 & Ал-102 & BT-6 \\
\hline$b, \mathrm{~mm}$ & 11.6 & 4.4 & 12.3 & 7.6 \\
\hline$b / d_{0}$ & 1.9 & 0.7 & 2.0 & 1.2 \\
\hline$V_{\mathrm{BL}}, \mathrm{m} / \mathrm{s}$ & 530 & 360 & 400 & 375 \\
\hline Тип разрушения преграды & Прокол & Прокол, прогиб преграды & $\begin{array}{l}\text { Прокол с частичной локализацией дефор- } \\
\text { мации на заключительной стадии пробития }\end{array}$ & $\begin{array}{l}\text { Лицевые отколы, } \\
\text { прокол, пробка }\end{array}$ \\
\hline$\left(L_{b}\right)_{\mathrm{FPD}} / b$ & 0.63 & 0.64 & 0.63 & 0.62 \\
\hline$\left(V_{0}\right)_{\mathrm{FPD}} / V_{\mathrm{BL}}$ & 0.50 & 0.47 & 0.56 & 0.53 \\
\hline$\left(L_{b}\right)_{\mathrm{PDF}} / b$ & 1.16 & 1.14 & 1.02 & 0.95 \\
\hline$\left[\left(V_{0}\right)_{\mathrm{PDF}}-\left(V_{0}\right)_{\mathrm{FPD}}\right] / V_{\mathrm{BL}}$ & 0.31 & 0.18 & 0.30 & 0.24 \\
\hline$\left[V_{\mathrm{BL}}-\left(V_{0}\right)_{\mathrm{PDF}}\right] / V_{\mathrm{BL}}$ & 0.19 & 0.36 & 0.13 & 0.23 \\
\hline$\left(S_{b}\right)_{\max } / d_{0}$ & 0.95 & 0.70 & 0.80 & 0.80 \\
\hline$\left(S_{b}\right)_{\max } / b$ & 0.50 & 0.98 & 0.40 & 0.64 \\
\hline$\left(V_{0}-V_{s}\right) / V_{0}\left(V_{0}=800 \mathrm{~m} / \mathrm{s}\right)$ & 0.19 & 0.16 & 0.15 & 0.17 \\
\hline
\end{tabular}

\section{Анализ разрушения преград}

Сравнительный анализ диаграмм пробития всех испытанных преград представлен в табл. 2.

Для этих преград установлены следующие различия в характере разрушения: пластичные преграды Ст3, Ст,69“Ш, Ал-102 разрушаются по типу прокола, тонкая преграда Ст,,69“Ш при пробитии испытывает деформацию прогиба; для прочной преграды из алюминиевого сплава Ал-102 на заключительной стадии пробития наблюдается срезание небольшой пробки.

Для прочной титановой преграды ВТ-6 в начале внедрения ударника имеет место прокол, сопровождающийся выкалыванием лицевой поверхности преграды, а затем срезается пробка. Для момента ПСП глубина лицевых отколов составила $4.0 \mathrm{~mm}$.

Далее происходит локализация деформации и адиабатический сдвиг части материала, т.е. образование пробки, и дальнейшее продвижение в преграду с выталкиванием пробки (измерения пробки после опыта дали то же значение $(7.6-4.0) \mathrm{mm}=3.6 \mathrm{~mm})$.

Интересно отметить, что пластическое деформирование тыльной поверхности всех преград начинается при одинаковой глубине внедрения ударника относительно толщины преграды $-\left(\left(L_{b}\right)_{\mathrm{FPD}} / b\right)=0.63$. При этом характерная скорость удара $\left(V_{0}\right)_{\mathrm{FPD}}$ для разных преград меняется слабо и составляет для преград толщиной более калибра в среднем $0.53 V_{\mathrm{BL}}$; лишь для тонкой преграды Ст,,69“Ш, где $\left(b / d_{0}\right)=0.7$, эта характеристика несколько ниже $-\left(V_{0}\right)_{\mathrm{FPD}}=0.47 V_{\mathrm{BL}}$.

На момент РПК - разрыва пластического купола путь ударника в пластичных преградах превышает тол- щину преграды (до 1.16b), а для прочной преграды BT-6 из-за образования пробки это значение меньше и составляет $\left(L_{b}\right)_{\mathrm{PDF}}=0.95 b$.

Развитие пластического купола в исследуемых преградах $\left[\left(V_{0}\right)_{\mathrm{PDF}}-\left(V_{0}\right)_{\mathrm{FPD}}\right]$ показывает зависимость от толщины преграды, изменяясь от $0.18 V_{\mathrm{BL}}$ для $\left(b / d_{0}\right)=0.7$ до $0.31 V_{\mathrm{BL}}$ для $\left(b / d_{0}\right) \approx 2.0$. Максимальная деформация тыльной поверхности $\left(S_{b}\right)_{\max } / d_{0}$ имеет наибольшее значение, равно 0.95 , для малопрочной стальной преграды Ст3 и уменьшается по мере увеличения прочности материала преграды.

Измерения запреградной скорости показали, что потеря начальной скорости в процессе пробития различных преград имеет близкие значения и составляет $(0.15-0.19) V_{0}$ для скорости стрелкового диапазона.

Повышение прочности преграды приводит к изменению вида ее разрушения: вместо интенсивного пластического деформирования значительных объемов материала преграды („прокол“) определяющей становится локализация пластической деформации в узкой области материала преграды в форме цилиндрической поверхности, что при повышении давления на фронте волны сжатия приводит к более раннему адиабатическому сдвигу материала по этой поверхности — „срезанию пробки“.

\section{Заключение}

Таким образом, проведенный анализ разрушения преград с различными физико-механическими характеристиками с помощью диаграмм пробития позволяет установить общие закономерности процесса и сделать количе- 
ственные оценки, характеризующие особенности деформирования и разрушения преград. По существу, диаграммы пробития - это экспериментально-графический метод оценки предельной пластичности преград в условиях их пробития и определения ПСП.

В целом эти данные позволяют оценить стойкость преград к ударному нагружению и их защитные свойства. Установленная на основе обширных экспериментов информация является особенно актуальной, так как получена на реальных конструкционных материалах в практически важном диапазоне скоростей взаимодействия.

\section{Финансирование работы}

В работе использованы результаты, полученные в ходе выполнения государственного задания Минобрнауки России, проект № 9.9036.2017/8.9.

\section{Список литературы}

[1] Захаров В.М., Табаченко А.Н., АФанасьева С.А. // ЖТФ. 2017. Т. 87. Вып. 7. C. 1003-1007. DOI: 10.21883/JTF.2017.07.44669.2106

[Zakharov V.M., Tabachenko A.N., Afanasieva S.A. // Techn. Phis. 2017. Vol. 62. N 7. P. 1019-1023.

DOI: $10.1134 / \mathrm{S} 1063784217070283]$

[2] Захаров В.М., Хорев И.Е. В сб.: Фундаментальные основы баллистического проектирования. Т. 2. СПб.: БГТУ „Военмех“, 2010. С. 93-96.

[3] Захаров В.М., Хорев И.Е. В сб.: Актуальные проблемы прочности. 53 Международная научная конференция. Часть 1. Витебск: УО ВГТУ, 2012. С. 212-214. 